\title{
Somatotype and Body Composition of Normal and Dysphonic Adult Speakers
}

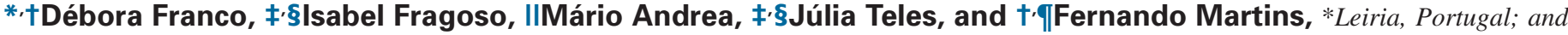 \\ $\dagger+\S \| \Upsilon$ Lisbon, Portugal
}

\begin{abstract}
Summary: Objective. Voice quality provides information about the anatomical characteristics of the speaker. The patterns of somatotype and body composition can provide essential knowledge to characterize the individuality of voice quality. The aim of this study was to verify if there were significant differences in somatotype and body composition between normal and dysphonic speakers.
\end{abstract}

Study Design. Cross-sectional study.

Methods. Anthropometric measurements were taken of a sample of 72 adult participants (40 normal speakers and 32 dysphonic speakers) according to International Society for the Advancement of Kinanthropometry standards, which allowed the calculation of endomorphism, mesomorphism, ectomorphism components, body density, body mass index, fat mass, percentage fat, and fat-free mass. Perception and acoustic evaluations as well as nasoendoscopy were used to assign speakers into normal or dysphonic groups.

Results. There were no significant differences between normal and dysphonic speakers in the mean somatotype attitudinal distance and somatotype dispersion distance (in spite of marginally significant differences $[P<0.10]$ in somatotype attitudinal distance and somatotype dispersion distance between groups) and in the mean vector of the somatotype components. Furthermore, no significant differences were found between groups concerning the mean of percentage fat, fat mass, fat-free mass, body density, and body mass index after controlling by sex.

Conclusion. The findings suggested no significant differences in the somatotype and body composition variables, between normal and dysphonic speakers.

Key Words: somatotype-body composition-dysphonia-voice disorders-voice quality.

\section{INTRODUCTION}

The concept of voice quality is the result of a set of features constantly present in the speech production of a particular person., ${ }^{1,2}$ These characteristics include not only the organic component (relative to the structures of the vocal tract) but also the phonetic or functional component (the use of those structures, that is, the performed function). The study of these features is fundamental to characterize the voice quality of a particular speaker, especially when the speaker has a voice disorder or dysphonia.

Some challenges in the clinical practice of a speech and language therapist have been motivating the study of speech production variability. Issues such as slow or ineffective evolution and relapses in the rehabilitation process of the pathological voice make research in the intrinsic physical characteristics of the speaker important. These intrinsic physical characteristics of the speakers can explain their vocal individuality. Additionally, in our opinion, the identification of biomarkers (a naturally occurring characteristic by which a particular pathological or physiological process or disease can be identified) for dysphonia is of extreme importance for clinical practice. ${ }^{3,4}$

\footnotetext{
Accepted for publication November 24, 2015

From the *School of Health Sciences, Polytechnic Institute of Leiria, Leiria, Portugal; $\dagger$ Centro de Linguística (CLUL), University of Lisbon, Lisbon, Portugal; $\ddagger$ Centro Interdisciplinar de Estudo da Performance Humana (CIPER), University of Lisbon, Cruz Quebrada-Lisbon, Portugal; §Faculty of Human Kinetics, University of Lisbon, Cruz Quebrada-Lisbon, Portugal; \#Faculty of Medicine of Lisbon, University of Lisbon, Lisbon, Portugal; and the $\Psi$ Faculty of Letters, University of Lisbon, Lisbon, Portugal.

Address correspondence and reprint requests to Débora Franco, School of Health Sciences, Polytechnic Institute of Leiria, Campus 2, Morro do Lena, Alto do Vieiro, Apartado 4137,

2411-901 Leiria, Portugal. E-mail: debora.franco@hotmail.com

Journal of Voice, Vol. $\square \mathbf{\square}$, No. $\square \mathbf{\square}$, pp. $\square \square-\square$

$0892-1997$

(C) 2015 The Voice Foundation. Published by Elsevier Inc. All rights reserved.

http://dx.doi.org/10.1016/j.jvoice.2015.11.020
}

The voice phenomenon can be better understood if we analyze the morphological condition of the speaker. Many of the factors that determine the quality of the voice are beyond the control of the speaker. Differences in the size, shape, and muscular tone of the laryngeal structures may play a major role. Voices of men, women, and children reflect mainly anatomical differences, although intrinsic, anatomy-based features may be enhanced or diminished, depending on the sociocultural context. ${ }^{5}$ Also, family voice disorders have been suggested to be due to genetic effects rather than to environmental effects. ${ }^{6.7}$ Actually, etiological factors of dysphonia are well known: poor postural habits, hypertonicity associated with psychological states, personality, tone associated with pharyngolaryngeal reflux, neuromuscular abnormalities, and mass lesions. ${ }^{8,9}$ However, according to our knowledge, studies including body composition biomarkers have not been considered in the field of voice disorders until the present moment.

Biological patterns of voice production associated with physical body characteristics are not new concerns in the field of voice quality research; however, the results achieved are controversial and none of these studies included dysphonic speakers. ${ }^{6,10-21}$ Body size has been related to vocal tract morphology. ${ }^{10-14,16}$ Fitch and Giedd ${ }^{10}$ found differences in vocal tract morphology both in male and in female speakers, including changes in vocal tract length and in the relative proportions of the oral and the pharyngeal cavities, with consequences in formant frequencies. These sex differences were part of the vocal remodeling process that occurs during puberty in males. ${ }^{10} \mathrm{~A}$ deep male voice may be a predictor of body size (height and weight) and body shape (body configuration including measures of body circumferences and ratios derived from these measures). ${ }^{11}$ On the contrary, Collins, ${ }^{13}$ 
Künzel, ${ }^{20}$ González, ${ }^{14}$ and Hamdan et al ${ }^{15,16}$ could not find any association between vocal and body characteristics. Table 1 brings together information about recent studies.

Some vocal quality studies, which consider morphological variables and morphology, have been developed especially in the field of obesity and weight loss. ${ }^{17-19,22-24}$ Body weight and body fat volume appear to influence objective measures of voice quality, ${ }^{17,18,22}$ vocal aerodynamics,,${ }^{17,18}$ and phonatory range performance. ${ }^{17}$ The distribution pattern of fat mass $(\mathrm{FM})$ is derived from factors such as age, sexual dimorphism, morphological type, and age of obesity development. ${ }^{25}$ The FM parameter, in particular, is a body composition measure scarcely considered in voice research studies. Also, a comparison has never been made between dysphonic and normal speakers to verify the influence of the relative amount of body fat (percentage fat [Fat\%]) on voice quality. However, body fat should be analyzed as it can compromise the upper airway and the vocal tract (uvula, soft palate, and the posterior region of the tongue),${ }^{26}$ can diminish lung function (because of adipose tissue presented around the rib cage, abdomen, and in the visceral cavity), and can reduce functional residual capacity. ${ }^{27}$ Excessive fat accumulation in the larynx might also alter maximum phonation time, which would impair myoelastic and aerodynamic forces in the larynx adjustments, which are required for adequate phonation. ${ }^{18}$ The amount of fat in an individual or a population can be related to diminished quality of life and with the emergence of certain diseases, ${ }^{28,29}$ namely the incidence of laryngeal reflux, apnea syndrome, and obstructive sleep apnea, particularly in obese people. $^{18}$

Despite the importance of this subject, previous literature has mostly focused on variables such as weight and body mass index (BMI), ${ }^{10,13,14,17,19,23,24}$ which are not the most appropriate measures of body composition variability, and for that reason can condition the information that can be obtained and analyzed. In our opinion, body composition analysis must consider other morphological characteristics such as skull, neck, shoulder, chest, waist, and hip circumferences, shoulder-hip ratio, shoulderwaist ratio, waist-hip ratio, ${ }^{11}$ muscle mass, fat weight, extremity fat, ${ }^{15,16}$ trunk fat, ${ }^{15}$ extremity fat-free mass (FFM), trunk FFM, and body FFM. ${ }^{16}$

Moreover, the morphological type that encloses a set of morphological traits or characteristics and integrates an individual into a certain category, often called morphotype or morphological type, ${ }^{25,30}$ seems to be another biological feature to consider in the study of voice quality although it was possibly never studied in the field of voice disorders. Somatotype is synthetic information about body build and is normally associated with motor efficiency. ${ }^{31}$ The dimensional and proportional characteristics of an individual are related to postural changes,$^{32}$ and for this reason, head and thorax characteristics, in particular, can possibly be related to voice quality, ${ }^{33}$ but until the present moment they have not yet been studied.

Aforementioned studies, which tried to characterize voice production based on physical body aspects, ${ }^{6,10-21}$ reached few sustainable results and even controversial ones (like the influence of body characteristics on the pitch or fundamental frequency $[\mathrm{F} 0]$ parameters ${ }^{12-16}$ or the vocal differences between obese and nonobese speakers ${ }^{17-19,22-24}$, which need clarification in the near future. In addition, understanding the features of the dysphonic speaker is particularly important to define appropriate treatment strategies and prevent recurrences.

Therefore, despite the relevance of previous studies and the implications of the anatomic and physiological characteristics of speakers on voice production and in the characterization of vocal pathologies, it is important to persist in the study of postural and morphological characteristics, especially of the dysphonic speakers, to obtain an integral understanding of the voice phenomena. The aim of this study is to verify if normal and dysphonic speakers have different morphological characteristics, using more precise anthropometric methods such as somatotype and body composition.

\section{MATERIALS AND METHODS}

\section{Subjects}

The potential participants were largely recruited during the Week of Screenings of World Voice Day, in the Department of Ear, Nose and Throat (ENT), Voice and Communication Disorders, of the Santa Maria Hospital, Faculty of Medicine, University of Lisbon. Thereafter, other participants were recruited from the School of Health Sciences, Polytechnic Institute of Leiria, and from the Faculty of Medicine, University of Lisbon. The inclusion criteria were (1) age between 20 and 50 years, (2) Caucasians, (3) European Portuguese as their first language, (4) absence of functional respiratory changes, and (5) signed informed consent. The age range chosen for our sample aimed to exclude all subjects that were in morphological growth and vocal maturation processes, in menopausal age, and with a clear decline in morphological and vocal abilities as a result of aging. To assess functional respiratory changes, all the recruited patients were submitted to a spirometry exam in the Pulmonology Department of Santa Maria Hospital. In turn, subjects with musculoskeletal disease, craniofacial malformations, orthopedic trauma, altered spirometry values, neurological diseases, neck scarring from surgery, radiation therapy or trauma, and previous history of larynx surgery were excluded.

Smoking was not included as an exclusion criterion because etiology was not the aim of this study and because all individuals had performed a spirometry, as an eligibility exam, and only those with no functional respiratory pathology were selected.

Among the 91 individuals assessed, only 72 met all the inclusion criteria and did not evidence any exclusion criterion. They were screened in the following sequence: body composition analysis and then voice quality evaluation. Our sample constituted 35 males (48.61\%) and 37 females (51.39\%). The male mean age was 32.43 years (standard deviation $[S D]=9.94$ ) and the female mean age was 31.74 years $(S D=10.52)$. The individuals were classified into two groups: normal or dysphonic speakers. This classification was done on the basis of their voice quality. The normal speakers group consisted of 40 participants (22 male and 18 female) with a mean age of $31.12 \pm 9.64$ years; the dysphonic speakers group was composed of 32 participants ( 13 male and 19 female) with a mean age of $33.72 \pm 10.92$ years. 


\section{TABLE 1.}

Current Findings Relating to Body Morphology and Vocal Characteristics

\begin{tabular}{|c|c|c|c|}
\hline $\begin{array}{l}\text { Author(s) } \\
\text { and Year }\end{array}$ & Body Composition Variable & Measures of Vocal Quality & Findings \\
\hline $\begin{array}{l}\text { Künzel } \\
\qquad(1989)^{20}\end{array}$ & Height, weight & Fundamental frequency (F0) & $\begin{array}{l}\text { The author intended to explore the effects } \\
\text { of somatic issues of the speaker on the } \\
\text { acoustic parameters but found no } \\
\text { relationship between the acoustic } \\
\text { parameters and the physical } \\
\text { parameters studied. }\end{array}$ \\
\hline $\begin{array}{l}\text { Collins } \\
\qquad(2000)^{13}\end{array}$ & $\begin{array}{l}\text { Body measures: weight, } \\
\text { height, hip and shoulder } \\
\text { width, and the men were } \\
\text { asked whether they had } \\
\text { chest hair; } \\
\text { Judges' ratings: } \\
\text { attractiveness, age, } \\
\text { weight and height, and } \\
\text { estimation about } \\
\text { muscularity and hairy } \\
\text { chest }\end{array}$ & $\begin{array}{l}\text { Five harmonic frequencies } \\
\text { (peak frequency and formant } \\
\text { frequencies) }\end{array}$ & $\begin{array}{l}\text { The author investigated the relationship } \\
\text { between male human vocal } \\
\text { characteristics and female judgments } \\
\text { about the speaker, but there was no } \\
\text { relationship between any vocal and } \\
\text { body characteristics. The judges' } \\
\text { estimates were incorrect except for } \\
\text { weight. }\end{array}$ \\
\hline $\begin{array}{l}\text { Fitch and } \\
\text { Giedd } \\
(1999)^{10}\end{array}$ & $\begin{array}{l}\text { Vocal tract length, height, } \\
\text { and weight }\end{array}$ & - & $\begin{array}{l}\text { There was a significant positive } \\
\text { correlation between vocal tract length } \\
\text { and body size. Additionally, the authors } \\
\text { also documented a sex difference in } \\
\text { vocal tract length that goes beyond sex } \\
\text { differences in size. The adult difference } \\
\text { in vocal tract length is caused by a } \\
\text { secondary "descent of the larynx," } \\
\text { which occurs in males at puberty. }\end{array}$ \\
\hline $\begin{array}{l}\text { González } \\
(2004)^{14}\end{array}$ & $\begin{array}{l}\text { Height, weight, and derived } \\
\text { measures ( } \log _{10} \text { weight, } \\
\text { BMI, body surface area) }\end{array}$ & $\begin{array}{l}\text { F0 and formant } \\
\text { parameters-first, second, } \\
\text { third, and fourth formants } \\
\text { (F1-F4) }\end{array}$ & $\begin{array}{l}\text { The author investigated the relationship } \\
\text { between formant frequencies and body } \\
\text { size in human adults. The relationship } \\
\text { within sex between formant parameters } \\
\text { and body size is very weak in human } \\
\text { adults. }\end{array}$ \\
\hline
\end{tabular}


TABLE 1.

(continued)

\begin{tabular}{|c|c|c|c|}
\hline $\begin{array}{l}\text { Author(s) } \\
\text { and Year }\end{array}$ & Body Composition Variable & Measures of Vocal Quality & Findings \\
\hline $\begin{array}{l}\text { Evans } \\
\text { et al. } \\
(2006)^{11}\end{array}$ & $\begin{array}{l}\text { Skull, neck, shoulder, chest, } \\
\text { waist, and hip } \\
\text { circumferences, shoulder- } \\
\text { hip ratio, shoulder-waist } \\
\text { ratio, waist-hip ratio }\end{array}$ & $\mathrm{F} 0, \mathrm{~F} 1, \mathrm{~F} 2, \mathrm{~F} 3, \mathrm{~F} 4$ & $\begin{array}{l}\text { The authors found a significant negative } \\
\text { relationship between formant } \\
\text { dispersion and measures of body size } \\
\text { as well as body shape. A significant } \\
\text { negative relationship was found } \\
\text { between the F0 (pitch) of the male voice } \\
\text { and measures of body shape including } \\
\text { shoulder and chest circumferences, and } \\
\text { shoulder-hip ratio. Also, weight was } \\
\text { significantly negatively correlated with } \\
\text { F0. }\end{array}$ \\
\hline $\begin{array}{l}\text { Evans } \\
\text { et al. } \\
(2008)^{12}\end{array}$ & $\begin{array}{l}\text { Various measures of } \\
\text { salivary testosterone }\end{array}$ & $\begin{array}{l}\text { F0, F1, F2, F3, F4, and formant } \\
\text { dispersion }\end{array}$ & $\begin{array}{l}\text { The authors concluded that there was a } \\
\text { negative relationship between } \\
\text { circulating levels of testosterone and F0 } \\
\text { in human males, with higher } \\
\text { testosterone indicating lower F0, } \\
\text { although the magnitude of the } \\
\text { relationship was larger than previously } \\
\text { observed. It was also found that there } \\
\text { was some limited evidence for a } \\
\text { relationship between circulating } \\
\text { testosterone and formant dispersion, } \\
\text { although this did not reach significance. } \\
\text { The authors believe that findings } \\
\text { confirm that vocal frequencies may } \\
\text { provide an honest signal of the } \\
\text { speaker's hormonal quality. }\end{array}$ \\
\hline $\begin{array}{l}\text { Hamdan } \\
\text { et al. } \\
(2013)^{16}\end{array}$ & $\begin{array}{l}\text { Height, weight, muscle } \\
\text { mass weight (MM), fat } \\
\text { weight, extremity fat, } \\
\text { extremity fat-free mass } \\
\text { (FFM), trunk FFM, total } \\
\text { body FFM, and BMI }\end{array}$ & $\begin{array}{l}\text { F0, F1, F2, F3, F4, and formant } \\
\text { dispersions }\end{array}$ & $\begin{array}{l}\text { A poor correlation was found between } \\
\text { formants, formants' dispersion, and } \\
\text { body mass variables. For vowel [a], F1 } \\
\text { and F4 correlated poorly with weight } \\
\text { and trunk FFM, and F4 correlated poorly } \\
\text { with MM and body FFM. For the [i] } \\
\text { vowel, there was a weak negative } \\
\text { correlation between F2, F3, and F4 and } \\
\text { height. Also, there was a negative } \\
\text { correlation between F2 and MM, trunk } \\
\text { FFM, and body FFM. For the [a] vowel, } \\
\text { F1-F2 interspace correlated positively } \\
\text { with fat weight, fat mass in the } \\
\text { extremities, and trunk, whereas F2-F3 } \\
\text { negatively correlated with weight. For } \\
\text { the [i] vowel, only F1-F2 negatively } \\
\text { correlated with weight and BMI. }\end{array}$ \\
\hline $\begin{array}{l}\text { Hamdan } \\
\text { et al. } \\
(2012)^{15}\end{array}$ & $\begin{array}{l}\text { Weight, fat weight, muscle } \\
\text { mass, extremity fat (\% fat } \\
\text { in the right leg, \% fat in } \\
\text { the left leg, \% fat in the } \\
\text { right arm, \% fat in the left } \\
\text { arm), \% fat in the trunk, } \\
\text { height, and BMI }\end{array}$ & $\begin{array}{l}\text { F0, relative average } \\
\text { perturbation (RAP), habitual } \\
\text { pitch, shimmer, noise-to- } \\
\text { harmonic ratio, voice } \\
\text { turbulence index, and } \\
\text { maximum phonation time } \\
\text { (MPT) }\end{array}$ & $\begin{array}{l}\text { The authors analyzed the correlation } \\
\text { between acoustic parameters and body } \\
\text { height, weight, and mass composition } \\
\text { in young males. They concluded that } \\
\text { there was a weak positive correlation } \\
\text { between shimmer, trunk fat, and muscle } \\
\text { mass. The body mass composition and } \\
\text { distribution do not correlate } \\
\text { significantly with the F0 and the } \\
\text { habitual pitch. }\end{array}$ \\
\hline
\end{tabular}


TABLE 1.

(continued)

\begin{tabular}{|c|c|c|c|}
\hline $\begin{array}{l}\text { Author(s) } \\
\text { and Year }\end{array}$ & $\begin{array}{c}\text { Body } \\
\text { Composition } \\
\text { Variable }\end{array}$ & $\begin{array}{c}\text { Measures } \\
\text { of Vocal } \\
\text { Quality }\end{array}$ & Findings \\
\hline $\begin{array}{l}\text { Da Cunha } \\
\text { et al. } \\
(2009, \\
2011)^{18,22}\end{array}$ & $\mathrm{BMI}$ & $\begin{array}{l}\text { GIRBAS scale-grade, } \\
\text { instability, roughness, } \\
\text { breathiness, asthenia, and } \\
\text { strain parameters, and harsh } \\
\text { parameter; fundamental } \\
\text { frequency (F0), jitter, } \\
\text { shimmer, HNR, and MPT }\end{array}$ & $\begin{array}{l}\text { The authors found that grade of } \\
\text { dysphonia, instability, hoarseness, } \\
\text { breathiness, asthenia, strain and harsh } \\
\text { parameters were significantly different } \\
\text { in the obese group compared with the } \\
\text { nonobese group. Obese individuals } \\
\text { exhibit murmuring or vocal fry and the } \\
\text { presence of voice strangulation at the } \\
\text { end of emission. Additionally, obese } \\
\text { people have an increase in their voice } \\
\text { perturbation parameters (jitter, } \\
\text { shimmer), in HNR parameter, and } \\
\text { reduced MPT. }\end{array}$ \\
\hline $\begin{array}{l}\text { Solomon } \\
\text { et al. } \\
(2011)^{23}\end{array}$ & BMI & $\begin{array}{l}\text { F0-range (Hertz and } \\
\text { semitones), SPL range, jitter } \\
\text { (rap), shimmer (apq), noise- } \\
\text { to-harmonic ratio, } \\
\text { dysphonia severity index } \\
\text { (DSI), as also severity, } \\
\text { roughness, breathiness, } \\
\text { strain, pitch, and loudness. } \\
\text { Other measures: MPT, } \\
\text { phonation threshold } \\
\text { pressure (PTP), laryngeal }\end{array}$ & $\begin{array}{l}\text { The authors investigated if obesity and } \\
\text { weight loss affect vocal function. No } \\
\text { significant differences were detected } \\
\text { between obese and nonobese groups } \\
\text { from the preoperative assessment. } \\
\text { There were no changes over time for } \\
\text { acoustic parameters, MPT, laryngeal } \\
\text { airway resistance, and airflow during a } \\
\text { sustained vowel for either group. PTP } \\
\text { changed significantly over time, but not } \\
\text { between groups. }\end{array}$ \\
\hline
\end{tabular}




\section{TABLE 1.}

(continued)

\begin{tabular}{|c|c|c|c|}
\hline $\begin{array}{l}\text { Author(s) } \\
\text { and Year }\end{array}$ & $\begin{array}{c}\text { Body } \\
\text { Composition } \\
\text { Variable }\end{array}$ & $\begin{array}{c}\text { Measures } \\
\text { of Vocal } \\
\text { Quality }\end{array}$ & Findings \\
\hline
\end{tabular}

\section{Ethics statement}

Ethical approval to undertake this study was obtained from the Ethics Committee for Health of the North Lisbon Hospital Center/ Faculty of Medicine of the University of Lisbon. The approval of the Administrative Council of Santa Maria Hospital/North Lisbon Hospital Center was also obtained. Informed consent was acquired from all participants before the examination.

\section{Procedure}

The experimental procedure was performed in the Department of ENT, Voice and Communication Disorders, of the Santa Maria Hospital, Faculty of Medicine, University of Lisbon. All individuals, after assessment for eligibility by an interview and a spirometry (by the Department of Pulmonology), underwent anthropometric and voice quality evaluations.

\section{Anthropometric evaluation}

Measurements were performed according to the standardized techniques adopted by the International Society for the Advancement of Kinanthropometry. All measurements were taken by the same anthropometrist, accredited by the International Society for the Advancement of Kinanthropometry. The technical error of measurement was lower than 5\% for skinfolds and lower than $1 \%$ for the other measurements. The instruments were calibrated before use. Anthropometric variables included body mass $(\mathrm{kg})$, height $(\mathrm{cm})$, sitting height $(\mathrm{cm})$; eight skinfold measurements $(\mathrm{mm})$, namely triceps, subscapular, biceps, iliac crest, supraspinale, abdominal, front thigh, medial calf; four girth measurements $(\mathrm{cm})$, namely arm relaxed, arm tensed, mid-thigh, calf; one length $(\mathrm{cm})$ acromiale-dactylion; and eight breadth measurements $(\mathrm{cm})$, namely biacromial, biiliocristal, transverse chest, anteriorposterior chest depth, biepicondylar humerus, stylion-ulnar, biepicondylar femur, malleolar.

Anthropometric measurements were obtained using portable measurement devices. Stature and heights were measured without shoes and head covers, using a portable anthropometer (Anthropometric Kit, Siber-Hegner GPM, Zurich, Switzerland) calibrated to the nearest $0.1 \mathrm{~cm}$. Body mass was measured with subjects wearing light clothing and no shoes, to the nearest $0.5 \mathrm{~kg}$, using a scale (Secca model 761 7019009; Vogel \& Halke, Hamburg, Germany) calibrated with known weights. Skinfold thickness was obtained using a skinfold caliper (Slim Guide, Rosscraft Innovations, Canada) (the tips at a pressure of $10 \mathrm{mg} / \mathrm{cm}^{2}$ ), lengths and diameters using a large sliding caliper (Anthropometric Kit, Siber-Hegner GPM, Zurich, Switzerland), and girths using a Rosscraft anthropometric tape (Rosscraft Innovations, Canada).

The BMI was calculated using the formula BMI = weight/ height $^{2}$, weight being expressed in kilograms and height expressed in meters. Body density (BD) was estimated using the Durnin and Womersley ${ }^{34}$ equation, which considers as predictors ethnicity, sex, and age of the participants. Density was converted to Fat $\%$ by the Siri equation, adapted from Heyward and Stolarczyk. ${ }^{35}$ FFM was also calculated.

Somatotype, originally proposed by Sheldon at 1940, was determined according to Carter and Heath. ${ }^{25}$ Characterization of the somatotype is done using a series of three digits. The first one relates to relative degree of adiposity (endomorphism). The second one relates to the degree of relative musculoskeletal development (mesomorphism), and the third one concerns the degree of linearity (ectomorphism). ${ }^{25}$

Besides the three somatotype components, two specific equations were also considered: (1) the two- and three-dimensional distances between somatopoints, namely the somatotype dispersion distance (SDD), which shows how far the localization of an individual somatopoint is from the centroid of the sample (mean somatopoint) when plotted on the somatogram; ${ }^{36}$ and (2) the somatotype attitudinal distance (SAD), which is the distance, in three dimensions, measured in somatotype component units, between an individual somatopoint and the centroid of the sample. ${ }^{37}$

\section{Voice quality evaluation}

The vocal assessment used was previously described by Franco et al. ${ }^{33}$ For the purpose of the present study, an interview (initially used for the assessment of eligibility to participate in the study), a nasoendoscopy, as well as perceptual and acous- 
TABLE 2.

Vocal Acoustic Characterization of Normal and Dysphonic Speakers

\begin{tabular}{|c|c|c|c|c|c|c|}
\hline \multirow[b]{2}{*}{ Acoustic Parameters } & \multicolumn{3}{|c|}{ Normal Speakers } & \multicolumn{3}{|c|}{ Dysphonic Speakers } \\
\hline & $\mathrm{N}$ & $\mathrm{M}$ & SD & $\mathrm{N}$ & $\mathrm{M}$ & SD \\
\hline \multicolumn{7}{|l|}{ [a] } \\
\hline F0 & 40 & 163.11 & 57.40 & 32 & 183.24 & 53.42 \\
\hline Intensity & 40 & 75.58 & 4.44 & 32 & 73.09 & 6.05 \\
\hline Jitter & 40 & 0.32 & 0.11 & 32 & 0.51 & 0.34 \\
\hline Shimmer & 40 & 2.03 & 0.62 & 32 & 3.64 & 1.97 \\
\hline HNR & 40 & 26.83 & 2.83 & 32 & 21.06 & 4.24 \\
\hline \multicolumn{7}{|l|}{ [i] } \\
\hline F0 & 40 & 210.53 & 77.37 & 32 & 225.29 & 67.96 \\
\hline Intensity & 40 & 75.53 & 4.65 & 32 & 74.71 & 4.51 \\
\hline Jitter & 40 & 0.20 & 0.10 & 32 & 0.33 & 0.15 \\
\hline Shimmer & 40 & 0.90 & 0.36 & 32 & 1.54 & 1.23 \\
\hline HNR & 40 & 30.93 & 3.21 & 32 & 26.82 & 2.93 \\
\hline \multicolumn{7}{|l|}{ [u] } \\
\hline F0 & 40 & 210.74 & 86.66 & 32 & 221.06 & 63.93 \\
\hline Intensity & 40 & 76.97 & 4.93 & 32 & 75.71 & 5.57 \\
\hline Jitter & 40 & 0.18 & 0.09 & 32 & 0.37 & 0.26 \\
\hline Shimmer & 40 & 1.06 & 0.40 & 32 & 1.50 & 0.59 \\
\hline HNR & 40 & 33.98 & 3.22 & 32 & 28.95 & 2.50 \\
\hline
\end{tabular}

tic evaluations were used to ensure an adequate judgment of the speakers' voice quality. Subjects were classified as normal or dysphonic speakers according to the methodology described by Guimarães and Abberton. ${ }^{38}$ Consequently, a speaker was classified as dysphonic when he or she experienced at least two of the following conditions: (1) vocal complaints for more than 15 days, (2) evidence of structural lesion, or (3) alterations in laryngeal dynamics that are reflected perceptually and acoustically. We considered vocal complaints to be permanent or frequent episodic voice problems not related with respiratory tract disease or allergic situations. ${ }^{38}$

For the acoustic and perceptual assessment, voices were recorded in a Faraday cage. We used a Marantz PMD660 (Kanagawa, Japan) with a Beyerdynamic TG H74c XLR (BK) condenser unidirectional headset microphone (Heilbronn, Germany), positioned laterally to the lips, keeping a constant distance of $5 \mathrm{~cm}$ for all participants. The corpus was collected in mono, with 32 bits, and a sampling frequency of $44,100 \mathrm{~Hz}$. The vocal behaviors, performed at a comfortable pitch and intensity level, were sustained vowels and continuous speech (conversation and reading). ${ }^{39}$ The sustained vowels are a stable behavior of the phonatory phenomena. Two samples were collected for each vowel and the most representative vowel sample was selected - that is, the natural tone and intensity normally used by the speaker. ${ }^{39}$ The European Portuguese vowels [u], [i], and [a], corresponding to the extreme positions of the vowel phonetic system, were considered in this study. The conversation was about an action image that permits spontaneous speech samples and, obviously, a more habitual pitch. ${ }^{40}$ The text that was read was the Portuguese version of "The Story of Arthur the Rat" (290 words), tried, pretested, and tested by Guimarães and Abberton. ${ }^{38}$
Acoustic assessment was based on the following physical parameters: F0, intensity of the acoustic signal, jitter, shimmer, and harmonic-to-noise ratio (HNR) ${ }^{41-43}$ These acoustic parameters were selected considering previous studies that tried to characterize vocal quality based on speakers' morphological issues, namely $\mathrm{F} 0,{ }^{24}$ intensity, ${ }^{17}$ and voice perturbation parameters. ${ }^{17,18,22,24}$

The acoustic analysis was performed with the Praat software (Version 5.3.23, Amsterdam, The Netherlands; Boersma and Weenink ${ }^{44}$ ). For the vowel analysis, we only considered the medial portion (about $1.5 \mathrm{~s}$ ) of the sustained phonation evaluated, as it corresponds to the more stable signal portion. ${ }^{14}$ All acoustic parameters were obtained automatically from the selected portion of the signal.

The reference values of perceptive evaluation and acoustic measures, used to decide the diagnosis, were in accordance with Hirano, ${ }^{45}$ Guimarães and Abberton, ${ }^{38}$ Behlau et al,${ }^{46}$ and Mendes and Castro. ${ }^{47}$ Acoustic characteristics of the speakers were presented in Table 2. To ensure the reliability and validity of the perceptual and acoustic evaluation, we used unambiguous definitions and terminology, as well as five samples of speech and an experienced evaluator well trained in the methodology adopted. To complement the ENT evaluation and acoustic analysis, voices were classified as no perceptual deviation, mild, moderate, and severe deviation $(0,1,2$, and 3$)$. A speaker who obtained a score $\geq 1$ was considered dysphonic. ${ }^{45,48-51}$ In the case of acoustic variables, individuals with intensity values different from $70 \mathrm{~dB}$, with values higher than $0.5 \%$ for the jitter, higher than $3 \%$ for the shimmer, and/or lower than $7 \mathrm{~dB}$ in the case of HNR parameter were considered dysphonic subjects.

Also referent to the acoustic variables, individuals with F0 values substantially different from those described by Guimarães 
TABLE 3.

Descriptive Measures of Demographic Variables of Subjects According to Sex (N = 72)

\begin{tabular}{llcc}
\hline & & Male & Female \\
\cline { 3 - 4 } Characteristics & & $n(\%)$ & $n(\%)$ \\
\hline Sex & & $35(48.61)$ & $37(51.39)$ \\
Education level & Middle school & $6(17.14)$ & $3(8.11)$ \\
& High school & $18(51.43)$ & $18(48.65)$ \\
Dental characterization & College & $11(31.43)$ & $16(43.24)$ \\
& Without alteration & $32(91.43)$ & $26(70.27)$ \\
& Orthodontic braces & $0(0.00)$ & $3(8.11)$ \\
Smoker & Orthodontic retainers & $1(2.86)$ & $1(2.70)$ \\
& Dental prosthesis & $2(5.71)$ & $7(18.92)$ \\
Age $(\mathrm{y})$ & No & $20(57.14)$ & $32(81.08)$ \\
Height $(\mathrm{cm})$ & Yes & $15(42.86)$ & $7(18.92)$ \\
Weight $(\mathrm{kg})$ & & $M(S D)$ & $M(S D)$ \\
BMl $\left(\mathrm{kg} / \mathrm{m}^{2}\right)$ & & $32.43(9.94)$ & $32.14(10.65)$ \\
& & $174.65(6.65)$ & $161.47(5.40)$ \\
& & $74.40(13.43)$ & $58.34(10.01)$ \\
& & $24.45(4.53)$ & $22.35(3.56)$
\end{tabular}

and Abberton ${ }^{38}$ (vowel [a]: $199.5 \pm 36.8 \mathrm{~Hz}$ and $113.0 \pm 37.2 \mathrm{~Hz}$; vowel [i]: $212.7 \pm 41.3 \mathrm{~Hz}$ and $130.2 \pm 45.2 \mathrm{~Hz}$; vowel [u]: $214.0 \pm 44.2 \mathrm{~Hz}$ and $128.1 \pm 45.8 \mathrm{~Hz}$, for women and men respectively), with intensity values different from $70 \mathrm{~dB},{ }^{47}$ jitter values higher than $0.5 \%$, shimmer values higher than $3 \%$, and/ or HNR values less than $10 \mathrm{~dB}^{46}$ were considered to have a voice with dysphonic characteristics.

For the video endoscopy, the following equipment was used: Olympus OTV-SI Digital Processor, Olympus Enf Type V2 Pal (Olympus, Auckland, New Zealand), with a Sony DVO1000MD DVD recorder (Sony Corporation, Tokyo, Japan). We also recorded voice behavior during the nasoendoscopic exam with a Sennheiser EW100 G2 microphone (Wedemark, Germany). The participants performed the sustained [i] phonation with increasing frequency, standardized sentences, and quiet breathing. ${ }^{52}$ Laryngeal inspection was done by the ENT surgeon using a nasoendoscopic exam. The nasoendoscopy was intentionally performed after the acoustic recordings to avoid the possible disagreeable sensation that the nasoendoscopy causes through the nasal cavity and the pharynx in the speech recordings.

\section{Statistical data analysis}

Data were analyzed with SPSS Statistics 20 (IBM Corporation, Chicago, IL) and the statistical significance level was set at $5 \%$. Descriptive statistics measures were used to characterize the study sample: means and SDs for continuous variables, and frequencies and percentages for categorical variables. Independent samples $t$ tests were applied for the comparison of dependent variables (SAD, SDD, BD, BMI, Fat $\%$, FM, and FFM) in normal and dysphonic speakers. Because of the multivariate features of the somatotype, a one-way multivariate analysis of variance (MANOVA) was performed to evaluate if there were significant differences in the vector of somatotype components (endomorphism, mesomorphism, and ectomorphism) between normal and dysphonic speakers.

\section{RESULTS}

Our sample was constituted by 72 individuals: 35 males (48.61\%) and 37 females (51.39\%). They were assessed for eligibility by an interview and a spirometry. The descriptive characteristics of the participants' demographic variables are summarized in Table 3 , for both sexes.

Table 4 presents the means and standard deviations for height, weight, and endomorphism, mesomorphism, and ectomorphism components considering sex and dysphonia.

Independent samples $t$ tests were conducted to compare the mean of each anthropometric variable (SAD, SDD, BD, BMI, Fat $\%$, FM, and FFM) between dysphonic and nondysphonic groups. The normality and the homogeneity of variance assumptions of independent samples $t$ test were verified. Table 5 presents the means and standard deviations of anthropometric variables for normal and dysphonic speakers, according to sex, and the independent samples $t$ test results for the comparison of each anthropometric variable between normal and dysphonic speakers. Means and standard errors of SAD, SDD, BMI, BD, Fat\%, FM, and FFM for normal and dysphonic speakers are displayed in the bar charts presented in Figure 1.

There were no significant differences between normal and dysphonic speakers in the mean SAD, SDD, BD, BMI, Fat\%, FM, and FFM after controlling by sex. Even though no significant differences were found for any anthropometric variables, differences in SAD and SDD, between normal and dysphonic speaker groups, were marginally significant $(0.05<P<0.10)$. Furthermore, Cohen's $d$ effect sizes values regarding SAD and SDD variables exceeded Cohen's minimum value $(d=0.20)$ to be considered a small effect size.

The MANOVA was used to compare the mean vectors of somatotype components between normal and dysphonic speakers. Concerning the MANOVA assumptions, we found no significant departure from multivariate normality and we verified the equality of covariance matrices using Box's test. The MANOVA results revealed that there were no significant differences in the 
TABLE 4.

Descriptive Measures, Mean (SD), of Morphological Characteristics (Height, Weight, Endomorphism, Mesomorphism, and Ectomorphism) for Normal and Dysphonic Speakers According to Sex ( $N=72$ )

\begin{tabular}{lllllll}
\hline Characteristics & Height $(\mathrm{cm})$ & Weight $(\mathrm{kg})$ & Endo & Meso & Ecto \\
\hline Male & Normal speakers & $175.80(7.00)$ & $74.11(14.03)$ & $4.39(1.87)$ & $4.20(1.52)$ & $2.50(1.62)$ \\
& Dysphonic speakers & $172.70(5.74)$ & $74.88(12.89)$ & $4.35(1.53)$ & $4.65(1.28)$ & $1.81(1.24)$ \\
& Total & $174.65(6.65)$ & $74.40(13.43)$ & $4.37(1.73)$ & $4.37(1.43)$ & $2.24(1.51)$ \\
Female & Normal speakers & $162.29(5.45)$ & $58.50(11.10)$ & $5.12(1.57)$ & $3.34(1.30)$ & $2.44(1.18)$ \\
& Dysphonic speakers & $160.69(5.38)$ & $58.18(9.16)$ & $5.18(1.34)$ & $3.92(0.96)$ & $2.05(1.21)$ \\
& Total & $161.47(5.40)$ & $58.34(10.01)$ & $5.15(1.43)$ & $3.64(1.16)$ & $2.24(1.20)$ \\
\hline
\end{tabular}

Abbreviations: Endo, endomorphism; Ecto, ectomorphism; Meso, mesomorphism.

somatotype between normal and dysphonic groups (Wilks' $\Lambda=0.941, F(3,65)=1.348, P=0.267$; partial $\left.\eta^{2}=0.059\right)$ after controlling by sex and age. The somatotype components of normal and dysphonic participants with the correspondent groups' centroids are displayed in Figure 2. Despite not finding significant differences in the mean vectors of somatotype components between normal and dysphonic speakers, the partial eta squared measure revealed that there was a small effect size.

\section{DISCUSSION}

This research intended to study somatotype and body composition differences between normal and dysphonic speakers groups, taking into account body complexity as well as several implications underlying these subjects. According to our knowledge, up to the present date, no studies have considered the effects of body composition and somatotype on voice disorders.

High levels of mesomorphism or endomorphism are generally associated with low values of ectomorphism. Nevertheless, correlations between endomorphism and mesomorphism are variable. A high value of mesomorphism may be observed in individuals with very different amounts of endomorphism and the reverse situation can also occur. ${ }^{25,30}$ As seen in Table 4, the mean somatotype of normal speakers was 4.39-4.20-2.50 and 5.12-3.34-2.44, whereas those of the dysphonic speakers was 4.35-4.65-1.81 and 5.18-3.92-2.05, for males and females, respectively. The predominant somatotype of our sample was the meso-endomorph type for females of both groups, and the mesomorph-endomorph and the endomorph-mesomorph types for males in the case of normal and dysphonic speakers, respectively. Unfortunately, the studied sample was basically endomorph, not showing a somatotype representativeness that could help us to understand the impact of somatotype on voice quality.

Consequently, SAD and SDD mean values reflected this limitation and thus only marginally significant differences between normal and dysphonic speakers in the mean SAD and SDD ( $P=0.059$ and $P=0.072$, respectively) were obtained. Besides that, MANOVA results showed no significant differences between the somatotype of normal and dysphonic groups. Unfortunately, we did not find studies that compared somatotype in normal and in dysphonic speakers.

In developed countries and cities, body weight and fat ${ }^{30}$ have been showing a positive secular trend that may possibly be present in our sample. Especially, the females showed a higher value of endomorphism. This finding is relevant for the understanding of dysphonia because prevalence of voice disorders seem to be higher in females ${ }^{6,53,54}$ and in obese speakers. ${ }^{22,55}$ Individuals with morbid obesity have shown significant voice changes compared with nonobese subjects. Obese peoples' voices have more hoarseness, breathiness, with higher instability and crepitation parameters, as jitter, shimmer, and noise. . $2,55^{2}$

Our results may also be interpreted considering the hormonal influence on vocal development. ${ }^{15,56}$ Adipose tissue and

\section{TABLE 5.}

Descriptive Measures of Anthropometric Variables (SAD, SDD, BD, BMI, Fat\%, FM, and FFM), for Normal and Dysphonic Speakers Groups, and the Results of Independent Samples $T$ Test for the Comparison Between Groups

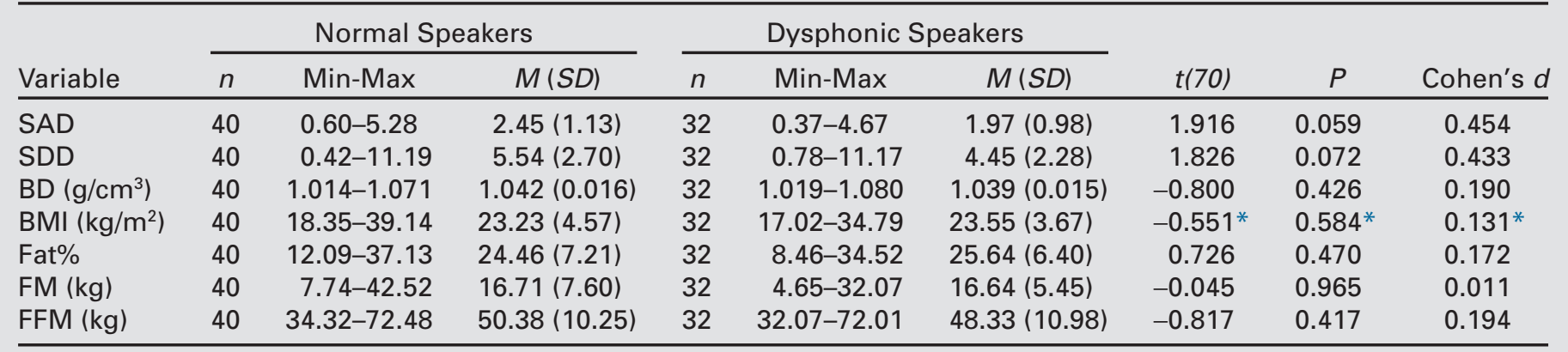

* After controlling by sex.

Abbreviations: BD, body density; BMI, body mass index; Fat\%, fat mass percentage; FM, fat mass; FFM, fat-free mass; SAD, somatotype attitudinal distance; SDD, somatotype dispersion distance. 

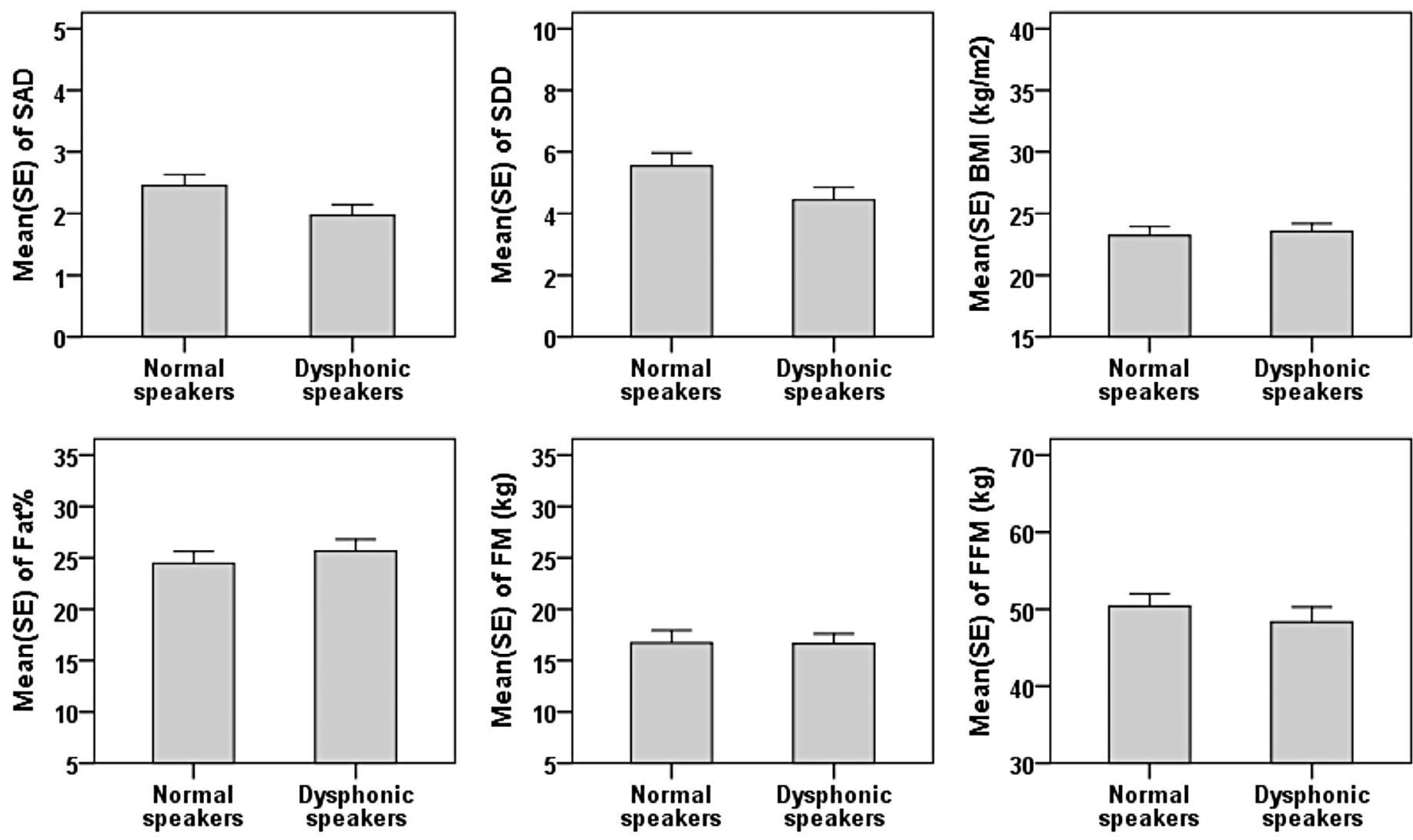

FIGURE 1. Mean and standard error (SE) of somatotype attitudinal distance (SAD), somatotype dispersion distance (SDD), body mass index (BMI), fat mass percentage (Fat\%), fat mass (FM), and fat-free mass (FFM) for normal and dysphonic speakers.

androgen levels do influence each other in a bidirectional and reciprocal way. Testosterone has a negative correlation with obesity and androgens influence the amount and fat distribution. ${ }^{56,57}$ Additionally, body size is associated with serum levels of estradiol, and free estradiol is positively correlated with percentage and trunk FM..$^{57,58}$ It is also known that menopause may likely affect obesity rates and body composition outcomes. However, we believe that this effect was controlled through the selected age range of our sample.

The increase in the BMI value at these ages and population segment (aged 20-50 years old and both sexes) usually suggests a rise in Fat\% ${ }^{31}$ Considering the marginally significant differences in the mean SAD and SDD between groups, the risk presented by overweight people to develop dysphonia could also have been observed in our study. However, that was not possible as our sample was composed of essentially endomorph subjects.

The sample size, although statistically rated, was obtained while taking into account restrictions of time and money, which constituted a limitation. It prevented us from having a sample that was demographically representative of the voice quality and morphological characteristics of subjects, regarding somatotype and body composition variables. Furthermore, the majority of the subjects were recruited during the Week of Voice Screenings at the Hospital Santa Maria. Those that normally adhere to such events may have particular occupations and morphologies, which may bias the results.
Generally, our results seem to be in accordance with González ${ }^{14}$ and Hamdan et al, ${ }^{15,16}$ although the authors did not study dysphonic speakers. González ${ }^{14}$ found a very weak relationship between formant parameters and body size (specifically, height, weight, BMI, and other derived measures). In Hamdan et al, ${ }^{15}$ the height, weight, muscle mass, and FM and its distribution do not significantly correlate with the F0 and with the habitual pitch in young males. Besides, there is no significant correlation between body composition (height, weight, muscle mass, fat weight, extremity fat, trunk fat, BMI, and other variables) and formant frequencies and dispersions. ${ }^{16}$

Although the morphology of normal and dysphonic speakers has not previously been compared, literature on voice quality presents a substantial inconsistency in results regarding morphological variables and acoustic parameters. ${ }^{6,10-21}$ One of the possible explanations for this is the variety of research questions, experimental designs, studied variables, and sample characteristics. Fitch and Giedd ${ }^{10}$ and Evans et al ${ }^{11}$ reported associations between vocal tract length and body size, verified by acoustic frequency parameters. However, Collins, ${ }^{13}$ González, ${ }^{14}$ Acurio et al, ${ }^{24}$ Solomon et al, ${ }^{23}$ and Hamdan et al ${ }^{15,16}$ were not in agreement with the previous authors because they have not been able to establish any significant associations. Barsties et al ${ }^{17}$ found differences in voice quality between individuals with different body composition characteristics, and Da Cunha et al ${ }^{18,22}$ studied the effects of changes in body size after bariatric surgery and concluded that body weight and body fat volume seem to 


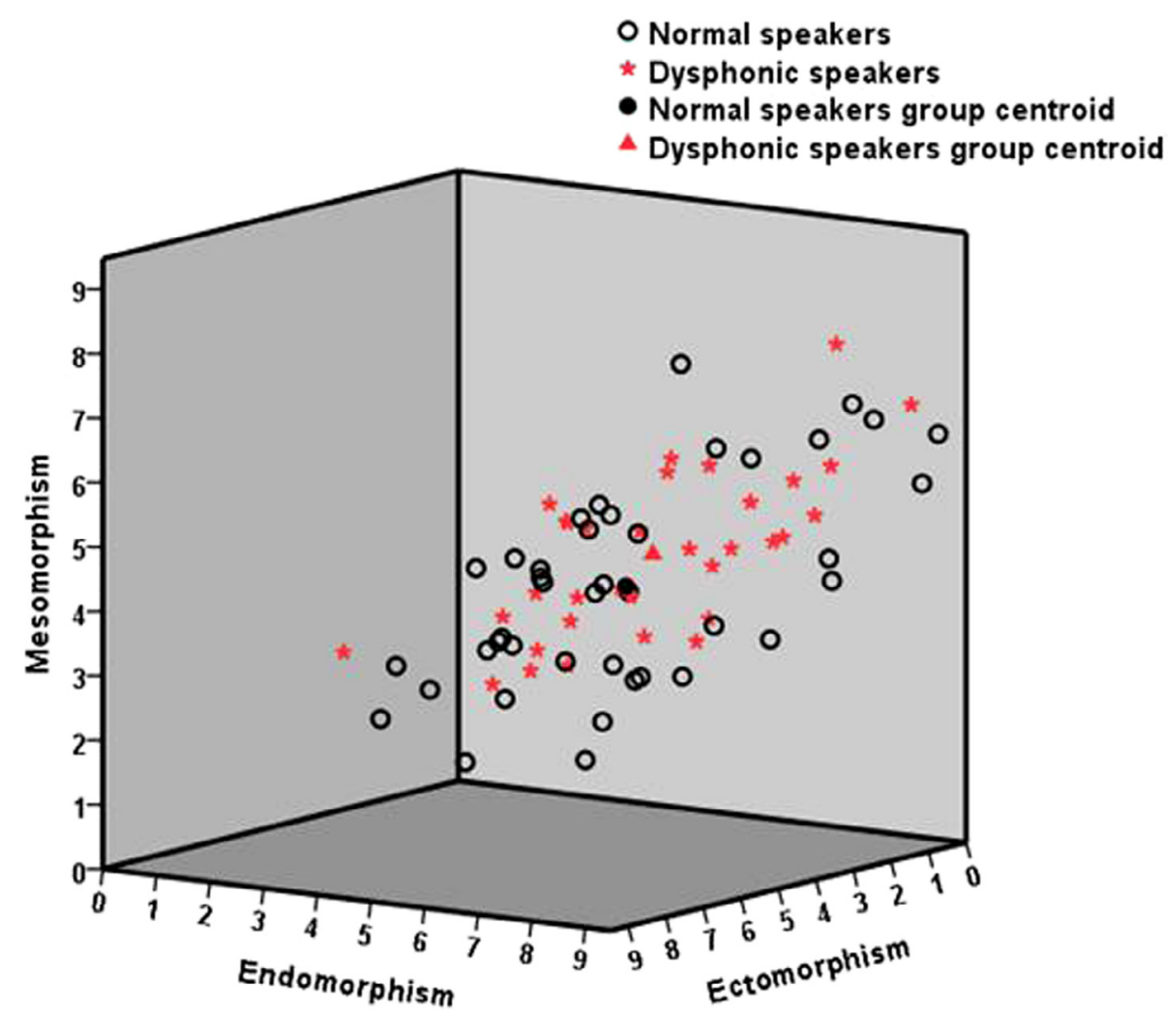

FIGURE 2. The three-dimensional scatter plot with the somatotype components of normal and dysphonic speakers.

influence acoustic parameters of voice quality (particularly perturbation parameters) and aerodynamic parameters. Nevertheless, authors like Solomon et $\mathrm{al}^{23}$ and Hamdan et $\mathrm{al}^{19}$ found no differences before and after surgery. Solomon et al, ${ }^{23}$ in particular, did not detect changes over time in acoustic parameters, maximum phonation time, laryngeal airway resistance, and airflow during a sustained vowel. Hamdan et $\mathrm{al}^{19}$ in like manner did not find changes in grade, roughness, and breathiness perceptual parameters and in acoustical parameters (particularly, average F0, habitual pitch, and the perturbation parameters). Acurio et al, ${ }^{24}$ in turn, presented no significant differences in perturbation acoustic parameters and maximum phonation time among BMI groups.

We present some important issues to be taken into account in future studies. Our work does not evaluate composed morphological variables, and little enlightening variables such as weight and BMI; this study assesses fat and FFM, which are much more informative and that should always taken into account in future studies. The sample size, considering that we are studying morphological variability, limits the interpretation of the findings. Therefore of this work, further studies are needed, involving a larger number of participants and a more representative sample of the adult population. In the future, we will have to assume other variables in the study of vocal production to attend to the morphological aspects of the speaker: (1) Obesity studies indicate that other pathologies frequently coexist with obesity, particularly gastroesophageal reflux, pharyngolaryngeal reflux, obstructive sleep apnea syndrome, and asthma. ${ }^{59-62}$ Their importance in the voice phenomena is widely known. ${ }^{10,63,64}$ In our study, we took some of these factors into consideration when applying the inclusion and the exclusion criteria. However, gastroesophageal reflux and pharyngolaryngeal reflux were not considered as exclusion criteria; (2) Growth, development, and metabolism attained through sex hormonal profile may have a considerable effect on voice quality and body composition. ${ }^{53} \mathrm{Sim}-$ ilarly, vocal frequencies may also provide an indication of the speaker's hormonal quality. ${ }^{11}$ However, our study did not consider hormonal variables.

\section{CONCLUSION}

Given the indivisible complexity of the body, we consider that a thorough evaluation of the individual is critical to the understanding of vocal pathology and to defining the vocal rehabilitation plan. Although the speakers are constituted of identical anatomical elements, they do not have the same physiological characteristics. Understanding the influence of body composition in the perspective of voice quality variation is important for the understanding of the speaker's own influences on their vocal production. This is particularly important in the study of possible recurrence of voice rehabilitation process and in the field of forensic phonetics so as to characterize and identify speakers.

No significant differences in the mean of SDD and SAD were found between normal and dysphonic speakers (in spite of marginally significant differences $[0.05<P<0.10]$ in SAD and SDD between groups). These results are in accordance with the MANOVA results, which demonstrated no significant differences in the vector of somatotype components between normal and dysphonic speakers. Additionally, the findings demonstrated no differences between groups for body composition 
variables, namely BD, BMI, FFM, FM, and Fat\%. Although this study has been methodologically built with quite informative variables regarding body composition, such as fat and FMM (instead of previous studies that have worked with composite variables such as BMI), we were not able to show a perfect relationship between laryngeal conditions and dysphonia, given the diversity of individual anatomical and physiological characteristics, compensation capacity, and possible vocal demands. However, taking into account the work already published on this topic and our results, there seems to be no doubt about the importance of this working area, and that further research is still necessary to determine morphological biomarkers related to vocal quality and vocal pathologies.

\section{Acknowledgments}

We are grateful for the diligence and time provided by the ENT, Voice and Communication Disorders Department, of the Hospital Santa Maria/Faculdade de Medicina of Universidade de Lisboa, and also all the volunteers.

\section{REFERENCES}

1. Abercrombie D. Elements of General Phonetics. Edinburgh: Edinburgh University Press; 1967.

2. Laver J. The Phonetic Description of Voice Quality. Cambridge: Cambridge University Press; 1980.

3. Biomarkers Definition Working Group. Biomarkers and surrogate endpoints: preferred definitions and conceptual framework. Clin Pharmacol Ther 2001;69:89-95.

4. Strimbu K, Tavel JA. What are biomarkers? Curr Opin HIV AIDS 2010;5:463-466.

5. Ní A, Gobl C. Voice source variation. In: Hardcastle WJ, Laver J, eds. The Handbook of Phonetic Sciences. USA: Blackwell Publishing; 1999:296-322.

6. Simberg S, Santtila P, Soveri A, et al. Exploring genetic and environmental effects in dysphonia: a twin study. J Speech Lang Hear Res. 2009;52:153163.

7. Roy N, Merril RM, Thibeault S, et al. Prevalence of voice disorders in teachers and the general population. J Speech Lang Hear Res. 2004;47:281293.

8. Morrison M. Pattern recognition in muscle misuse voice disorders: how I do it. J Voice. 1997;11:108-114.

9. Van Houtte E, Van Lierde K, Clayes S. Pathophysiology and treatment of muscle tension dysphonia: a review of the current knowledge. $J$ Voice. 2011;25:202-207.

10. Fitch WT, Giedd J. Morphology and development of the human vocal tract: a study using magnetic resonance imaging. J Acoust Soc Am. 1999;106:1511-1522.

11. Evans S, Neave N, Wakelin D. Relationships between vocal characteristics and body size and shape in human males: an evolutionary explanation for a deep male voice. Biol Psychol. 2006;72:160-163.

12. Evans S, Neave N, Wakelin D, et al. The relationship between testosterone and vocal frequencies in human males. Physiol Behav. 2008;93:783-788.

13. Collins SA. Men's voices and women's choices. Anim Behav. 2000;60:773780 .

14. González J. Formant frequencies and body size of speaker: a weak relationship in adult humans. J Phon 2004;32:277-287.

15. Hamdan AL, Al-Barazi R, Tabri D, et al. Relationships between acoustic parameters and body mass analysis in young males. $J$ Voice. 2012;26:144147

16. Hamdan AL, Al Barazi R, Khneizer G, et al. Formant frequency in relation to body mass composition. $J$ Voice. 2013;27:567-571.

17. Barsties B, Verfaillie R, Roy N, et al. Do body mass index and fat volume influence vocal quality, phonatory range, and aerodynamics in females? Codas. 2013;25:310-318.
18. Da Cunha MG, Passerotti GH, Weber R, et al. Voice feature characteristics in morbid obese population. Obes Surg. 2011;21:340-344.

19. Hamdan AL, Safadi B, Chamseddine B, et al. Effect of weight loss on voice after bariatric surgery. $J$ Voice. 2014;28:618-623.

20. Künzel HJ. How well does average fundamental frequency correlate with speaker height and weight? Phonetica. 1989;46:117-125.

21. Van Dommelen WA, Moxness BH. Acoustic parameters in speaker height and weight identification: sex-specific behavior. Lang Speech. 1995;38:267287.

22. Da Cunha MGB, Passerotti GH, Weber R, et al. Morbid obesity and its relationship to voice alterations. Arq Bras Cir Dig. 2009;2276-2281.

23. Solomon NP, Helou LB, Dietrich-Burns K, et al. Do obesity and weight loss affect vocal function? Semin Speech Lang. 2011;32:31-42.

24. Acurio J, Celis C, Perez J, et al. Acoustic parameters and salivary IL-6 levels in overweight and obese teachers. $J$ Voice. 2014;28:574-581.

25. Carter L, Heath B. Somatotyping Development and Applications. Cambridge: Cambridge University Press; 1990.

26. Horner RL, Mohiaddin RH, Lowell DG, et al. Sites and sizes of fat deposits around the pharynx in obese patients with obstructive sleep apnoea and weight matched controls. Eur Respir J. 1989;2:613-622.

27. Salome CM, King GG, Berend N. Physiology of obesity and effects on lung function. J Appl Physiol. 2010;108:206-211.

28. Nguyen DM, El-Serag HB. The epidemiology of obesity. Gastroenterol Clin North Am. 2010;39:1-7.

29. WHO. Obesity: preventing and managing the global epidemic. Report of a WHO consultation. World Health Organ Tech Rep Ser. 2000;894:1-253.

30. Vieira F, Fragoso I. Morfologia E Crescimento. 2nd ed. Cruz Quebrada, Portugal: Faculdade de Motricidade Humana; 2006.

31. Sterkowicz-Przybycień K. Technical diversification, body composition and somatotype of both heavy and light Polish ju-jitsukas of high level. Sci Sports 2010;25:194-200.

32. Araújo F, Lucas R, Alegrete N, et al. Individual and contextual characteristics as determinants of sagittal standing posture: a population-based study of adults. Spine J. 2014;14:2373-2383.

33. Franco D, Martins F, Andrea M, et al. Is the sagittal postural alignment different in normal and dysphonic speakers? J Voice. 2014;28:523, e1-523.e8.

34. Durnin JV, Womersley J. Body fat assessed from total body density and its estimation from skinfold thickness: measurements on 481 men and women aged from 16 to 72 years. Br J Nutr. 1974;32:77-97.

35. Heyward VH, Stolarczyk LM. Applied Body Composition Assessment. Champaign, IL: Human Kinetics Publishers; 1996.

36. Ross WD, Wilson BD. A somatotype dispersion distance. Res $Q$. 1973;44:372-374.

37. Ross WD, Carr R, Carter JEL. Anthropometry Illustrated (CD-Rom.). Surrey, CAN: Turnpike Electronic Publications, Inc.; 1999.

38. Guimarães I, Abberton E. Fundamental frequency in speakers of Portuguese for different voice samples. J Voice. 2005;19:592-606.

39. Parsa V, Jamieson DG. Acoustic discrimination of pathological voice: sustained vowels versus continuous speech. J Speech Lang Hear Res. 2001;44:327-339.

40. Baken RJ, Orlikoff RF. Clinical Measurement of Speech and Voice. San Diego, CA: Singular Publishing Group; 2000.

41. Eadie TL, Doyle PC. Classification of dysphonic voice: acoustic and auditory-perceptual measures. $J$ Voice. 2005;19:1-14.

42. Guimarães I. A Ciência e a Arte da Voz Humana. Alcabideche, Portugal: ESSA; 2007

43. Teles VC, Rosinha ACU. Acoustic analysis of formants and measures of the sonorous signal disturbance in non-smoker and non-alcoholic women without vocal complaints. Int Arch Otorhinolaryngol. 2008;12:523-530.

44. Boersma P, Weenink D. PRAAT: Doing Phonetics by Computer, Version 5.3.23. The Netherlands: University of Amsterdam; 2012.

45. Hirano M. Clinical Examination of Voice. New York, USA: Springer Verlag; 1981

46. Behlau M, Madazio G, Feijó D, et al. Avaliação de voz. In: Behlau M, ed. Voz: O Livro Do Especialista, Vol. 1. Rio de Janeiro, Brazil: Revinter; 2001:85-245.

47. Mendes A, Castro E. Acoustic analysis of voice assessment: phonatory tasks and acoustic parameters. Rev Port ORL. 2005;43:127-136. 
48. Hakkesteegt MM, Brocaar MP, Wieringa MH, et al. The relationship between perceptual evaluation and objective multiparametric evaluation of dysphonia severity. J Voice. 2008;22:138-145.

49. Lopez HAG, Mondain M, Bretèque BA, et al. Acoustic, aerodynamic, and perceptual analyses of the voice of cochlear-implanted children. $J$ Voice. 2013;27:523e1-523e17.

50. Schaeffer N, Sidavi A. Toward a more quantitative measure to assess severity of dysphonia: preliminary observations. $J$ Voice. 2010;24:556-563.

51. Yu P, Ouaknine M, Revis J, et al. Objective voice analysis for dysphonic patients: a multiparametric protocol including acoustic and aerodynamic measurements. $J$ Voice. 2001;15:529-542.

52. Lowell SY, Kelley RT, Colton RH, et al. Position of the hyoid and larynx in people with muscle tension dysphonia. Laryngoscope. 2012;122:370-377.

53. Andrews ML. Sex, gender, and effects on voice. In: Manual of Voice Treatment-Pediatrics through Geriatrics. 3rd ed. New York: Delmar Learning; 2006:488-523.

54. Herrington-Hall BL, Lee L, Stemple JC, et al. Description of laryngeal pathologies by age, sex, and occupation in a treatment-seeking sample. $J$ Speech Hear Disord. 1988;53:57-64.

55. Bortolotti P, Andrade e Silva MA. Caracterização da voz de um grupo de mulheres com obesidade mórbida acompanhadas no setor de cirurgia bariátrica da Irmandade Santa Casa de Misericórdia de São Paulo. Distúrb Comun. 2005;17:149-160.

56. Blouin K, Boivin A, Tchernof A. Androgens and body fat distribution. J Steroid Biochem Mol Biol. 2008;108:272-280.
57. Gates MA, Mekary RA, Chiu GR, et al. Sex steroid hormone levels and body composition in men. J Clin Endocrinol Metab. 2013;98:24422450.

58. Paxton RJ, King DW, Garcia-Prieto C, et al. Associations between body size and serum estradiol and sex hormone-binding globulin levels in premenopausal African American women. J Clin Endocrinol Metab. 2013;98:E485-E490.

59. Akerman MJ, Calacanis CM, Madsen MK. Relationship between asthma severity and obesity. J Asthma. 2004;41:521-526.

60. Di Francesco V, Baggio E, Mastromauro M, et al. Obesity and gastroesophageal acid reflux: physiopathological mechanisms and role of gastric bariatric surgery. Obes Surg. 2004;14:1095-1102.

61. Fujita RR, Moysés MG, Vuono IM. Ronco e apneia do sono. In: Campos CAH, Costa HOO, eds. Tratado De Otorrinolaringologia. São Paulo, Brazil: Rocca; 2002:637-643.

62. Simard B, Turcotte H, Marceau P, et al. Asthma and sleep apnea in patients with morbid obesity: outcome after bariatric surgery. Obes Surg. 2004; 14:1381-1388.

63. Rubin JS, Sataloff RT, Korovin G, Koufmann J, et al., eds. Gastroesophageal reflux and voice disorders. In: Diagnosis and Treatment of Voice Disorders. New York: Igaku-Shoin; 1995:161-175.

64. Sataloff R, Castell O, Satalof M, et al. Reflux and other gastroenterological conditions that may affect the voice. In: Sataloff RT, ed. Professional Voice: the Science and Art of Clinical Care. 2nd ed. San Diego: Singular Publishing Group; 1997. 